Special Issue on ISAE 2013

NOTE

\title{
Analysis of Mathematical Model of Hit Phenomena Stage Actors of Japan
}

\author{
Yasuko KAWAHATA*, Etsuo GENDA*, Hidehiko KOGUCH**, \\ Koki UCHIYAMA*** and Akira ISHII**** \\ * Graduate School of Design, Kyushu University, 6-10-1 Hakozaki, Higashi-ku, Fukuoka 812-8581, Japan \\ ** Perspective Media, 3-6-9 Kakinokizaka, Meguro-ku, Tokyo 152-0022, Japan \\ *** Hottolink, Kanda-nishikicho, Chiyoda-ku, Tokyo 101-0054, Japan \\ **** Tottori University, Koyama, Tottori 680-8554, Japan
}

\begin{abstract}
A mathematical model for the hit phenomenon in entertainment within a society is presented as a stochastic process of interactions of human dynamics. The model uses only the time distribution of advertisement budget as an input, and word-of-mouth (WOM) represented by posts on social network systems is used as data to compare with the calculated results. The unit of time is a day. The calculations for the Japanese motion picture market based on to the mathematical model agree very well with the actual residue distribution in time. The model is applied also to weekly TV drama.

We show that prediction is possible in appearance to the number of news and TV and stage with regard reputation of stage actors in Japan in this paper.
\end{abstract}

Keywords: Hit phenomena, WOM, Advertisement, Kabuki, Actor

\section{INTRODUCTION}

Evaluation of art and music is very important for art management and art marketing. In recent years, the social media like Facebook, Twitter and blogs has been very popular, so that the evaluation of arts, music and plays can be evaluated not only by the experts but also using the social media. [1-3]

We can assume that communication in the SNS society is very similar to that in real society. Thus, we can use the huge stock of digital data of human communication as observation data of real society [4-7]. Using this observed huge data (so -called "Big Data"), we can apply the method of statistical physics to social sciences. Since word-of-mouth (WOM) is very significant in marketing science [8-12], such analysis and prediction of the digital WOM in the sense of statistical physics become very important today like a Figure 1. Recently, we present a mathematical theory for hit phenomena where effect of advertisement and propagation of reputation and rumors due to human communications are included as the statistics physics of human dynamics [1] In this paper, we analyzed the 12 generation Ichikawa Danjuro XII and Matsumoto Koshiro IX as stage actors on behalf of Japan. From Figure 2 , They are a Kabuki actors are traditional Japanese performing arts, which continued from the 17th century $[14,15]$.
Matsumoto Koshiro XI also Ichikawa Danjulo XII while being kabuki actors are a traditional arts of Japan, the Appeared in such dramas and movies not only stage unlike the Edo period. We want to show that this is analysis is possible with regard reputation of an actor to play an active part in Japan, not only the group to which this method plays an active part in the world. In this paper, the responses in social media are observed using the social media listening platform presented by Hottolink. Using

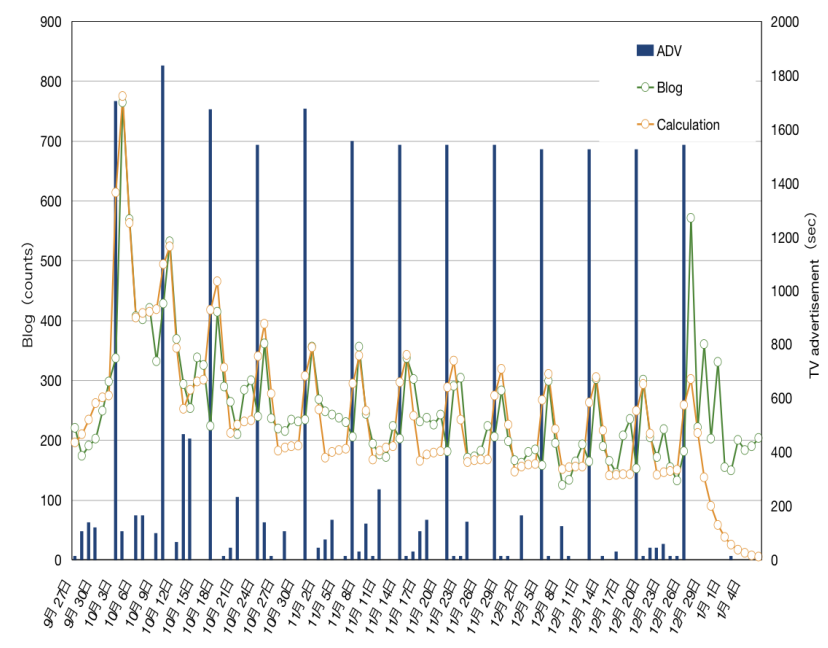

Figure 1: The calculation and the observed data for a weekly TV drama in Japan. The histogram means the observed exposure on each movies on TV counted in unit of seconds The green curve corresponds the observed number of daily blog posting. And the orange curve corresponds to our calculation. [1] 


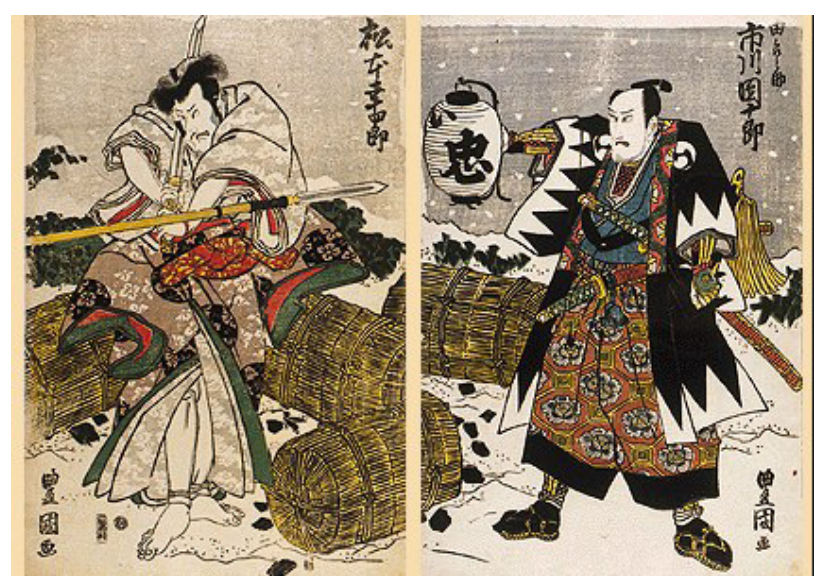

Figure 2: Koshiro Matsumoto and Ichikawa Danjulo is a Kabuki actor is a traditional Japanese performing arts, which continued from the 17th century, leading to the generation of the now generation to generation the family name is inherited. (Picture from Waseda Engeki Museum).

the data set presented by M Data Co.Ltd monitors the exposure of each films. [14,15]

\section{HIT PHENOMENA}

\subsection{Intention of each person for enjoying entertainment}

We start the modeling from the viewpoint of the individual audiences. We define intention for entertainmentof the individual audiences, labeled $\mathrm{i}$, at time $\mathrm{t}$ as $I_{i}(t)$. We assume that the number of products adopted until time $t$ can be written as

$$
Y(t)=p \int_{t_{0}}^{t} \sum_{i=1}^{N} I_{i}(t) d t
$$

where $N$ is the maximum number of adopted persons, $p$ is the price of the contents and $t_{0}$ is the release date of the contents or events. Thus, our problem is to define the equation of the intention for entertainment of each consumer $I_{i}(t)$. We consider the modeling of the effects of advertisements, WOM, and rumor for the intention for entertainment in the following subsections.

The advertisement effect through mass media like TV, newspapers, magazines, the Web, Facebook, or Twitter is modeled as an external force for the equation of the intention for entertainment of the individual consumer:

$$
\frac{d I_{i}(t)}{d t}=c_{i} A(t)
$$

where $A(t)$ is the time distribution of the effective advertisement effect per unit time and the coefficient describes the impression of the advertisement for audience $i$. The external force $A(t)$ can be considered trends in the world or political pressure on the market.

Usually, a film's success spreads through WOM. Such WOM sometimes has a very significant effect on the success of the movie. Thus, the WOM effect should be included in our theory. The WOM effect should be distinguished into two types: WOM direct from friends, and indirect WOM as rumors. We name the WOM effect between friends direct communication, because customers obtain information directly from their friends. In the previous paper [1], we include also the communication between non-adopters. It is very significant for movie entertainment, especially before the opening of the movie. Let us consider that person $i$ hears information from person $j$. The probability per unit of time for the information to affect the intention for entertainment of person $i$ can be described as $D_{i j} I_{j}(t)$, where $I_{j}(t)$ is the intention for entertainment of person $j$ and $D_{i j}$ is the coefficient of the direct communication. Thus, we can write the effect of the direct communication as follows:

$$
\sum_{j=1}^{N} D_{i j} I_{j}(t)
$$

where the summation is done without $j=i$.

In this paper, rumor effect is named indirect communication. In this form of communication, a person hears a rumor while chatting on the street, overhearing a conversation from the next table in a restaurant or on a train, or finds the rumor in blogs or on Twitter. To construct the theory using mathematics, we focus on one person who listens to a conversation happening around him/her. Let us consider that person $I$ overhears the conversation between person $\mathrm{j}$ and person $k$. The strength of the effect of the conversation can be described as $D_{j k} I_{j}(t) I_{k}(t)$. The probability per unit time for the conversation to affect the intention for entertainment of person $i$ is defined as $Q_{i j k} D_{j k} I_{j}(t) I_{k}(t)$, where $Q_{i j k}$ is the coefficient. Thus, the indirect communication coefficient can be defined as $P_{i j k}=Q_{i j k} D_{j k}$.

Therefore, direct communication is two-body interaction and indirect communication is three-body interaction. Thus, our theory for the hit phenomenon like hit movies can be described as the equation of the purchase intention of person $i$ with two-body interaction and three-body interaction terms.

According to the Ref. 1, we write down the equation of intention for entertainment at the individual level as

$$
\frac{d I_{i}(t)}{d t}=-a I_{i}(t)+\sum_{j} d_{i j} I_{j}(t)+\sum_{j} \sum_{k} h_{i j k} d_{j k} I_{j}(t) I_{k}(t)+f_{i}(t)
$$


where $d_{i j}, h_{i j k}$, and $f_{i}(t)$ are the coefficient of the direct communication, the coefficient of the indirect communication, and the random effect for person $i$, respectively. We consider the above equation for every consumer so that $i=1, \ldots, N_{p}$.

Taking the effect of direct communication, indirect communication, and the decline of audience into account, we obtain the above equation for the mathematical model for the hit phenomenon. The advertisement and publicity effect for each person can be described as the random effect $f_{i}(t)$.

Eq. (12) is the equation for all individual persons, but it is not convenient for analysis. Thus, we consider here the ensemble average of the intention for entertainment of individual persons as follows:

$$
\langle I(t)\rangle=\frac{1}{N} \sum_{i} I_{i}(t)
$$

Taking the ensemble average of Eq. (12), we obtain for the left-hand side:

$$
\left\langle\frac{d I_{i}(t)}{d t}\right\rangle=\frac{1}{N} \sum_{i} \frac{d I_{i}(t)}{d t}=\frac{d}{d t}\left(\frac{1}{N} \sum_{i} I_{i}(t)\right)=\frac{d\langle I\rangle}{d t}
$$

For the right-hand side, the ensemble average of the first, second, and third is as follows:

$$
\begin{aligned}
&\left\langle-a I_{i}\right\rangle=-a \frac{1}{N} \sum_{i} I_{i}(t)=-a\langle I(t)\rangle \\
&\left\langle\sum_{j} d_{i j} I_{j}(t)\right\rangle=\left\langle\sum_{j} d I_{j}(t)\right\rangle=\frac{1}{N} \sum_{i} \sum_{j} d I_{j}(t)=\sum_{i} d \frac{1}{N} \sum_{j} I_{j}(t)=N d\langle I(t)\rangle \\
&\left\langle\sum_{j} \sum_{k} p_{i j k} I_{j}(t) I_{k}(t)\right\rangle=\left\langle p \sum_{j} \sum_{k} I_{j}(t) I_{k}(t)\right\rangle \\
&=\frac{1}{N} \sum_{i} p \sum_{j} \sum_{k} I_{j}(t) I_{k}(t) \\
&=\sum_{i} p \frac{1}{N} \sum_{j} \sum_{k} I_{j}(t) I_{k}(t) \\
&=N p \sum_{i} \frac{1}{N} \sum_{j} I_{j}(t) \frac{1}{N} \sum_{k} I_{k}(t) \\
&=N^{2} p\langle I(t)\rangle^{2}
\end{aligned}
$$

where we assume that the coefficient of the direct and indirect communications can be approximated to be

$$
\begin{aligned}
& d_{i j} \cong d \\
& h_{i j k} d_{j k}=p_{i j k} \cong p
\end{aligned}
$$

under the ensemble average.

For the fourth term, the random effect term, we consider that the random effect can be divided into two parts: the collective effect and the individual effect:

$$
\begin{aligned}
& f_{i}(t)=\langle f(t)\rangle+\Delta f_{i}(t) \\
& \left\langle f_{i}(t)\right\rangle=\frac{1}{N} \sum_{i} f_{i}(t)=\langle f(t)\rangle
\end{aligned}
$$

where $\Delta f_{i}(t)$ means the deviation of the individual external effects from the collective effect, $\left\langle f_{i}(t)\right\rangle$. Thus, we consider here that the collective external effect term $\left\langle f_{i}(t)\right\rangle$ corresponds to advertisements and publicity to persons in the society. The deviation term $\Delta f_{i}(t)$ corresponds to the deviation effect from the collective advertisement and publicity effect for individual persons, which we can assume to be

$$
\left\langle\Delta f_{i}(t)\right\rangle=\frac{1}{N} \sum_{i} \Delta f_{i}(t)=0
$$

Therefore, we obtain the equation for the ensemble-averaged purchase intention in the following manner as shown in ref. 9:

$$
\frac{d\langle I(t)\rangle}{d t}=-a\langle I(t)\rangle+D\langle I(t)\rangle+P\langle I(t)\rangle^{2}+\langle f(t)\rangle
$$

where

$$
\begin{aligned}
& N d=D \\
& N^{2} p=P
\end{aligned}
$$

Eq. (13) can be applied to the intention for entertainment in the real market.

\subsection{Stages and News}

Stages and News are the very important factor to increase the intention of each person for enjoying entertainment. Stages and News are done at Concerts Hall, Live House, TV, newspaper and other media. We consider the advertisement effect as an external force term $A(t)$ to the intention as follows,

$$
\frac{d I_{i}}{d t}=C_{a d v} A(t)+\sum_{j} D_{i j} I_{j}(t)+\sum_{j} \sum_{k} P_{i j k} I_{j}(t) I_{k}(t)
$$

where $D_{i j}$ is the factor for the direct communication and $P_{i j k}$ is the factor for the indirect communication. The factor $C_{a d v}$ corresponds to the strength of the impression of the media or Concerts exposure for each advertising campaign. Because of the term of the indirect communication, this equation is a nonlinear equation. If we consider Stages and News, we can solve the equation by including several effect of the advertisement in the following way,

$$
C_{a d v} A(t) \Rightarrow \sum_{i} C_{i} A_{i}(t)
$$


where each coefficient $C_{i}$ corresponds to the each advertisement and Stages and News counts and can be determined by using the random number technique introduced in Ref. [1]. The actual formula used in the calculation to analyze the SNS response are introduced in detail in Ref. [1].

\section{RESULTS}

Here, we show the results for Matsumoto Koushiro IX. In Figure 3, we show the Monthly number of Stages and News, 2007-2012. [18-20]

There are a tendency to take place in monthly units drama and stage performances of contemporary theater and Kabuki in Japan is why we have to measure monthly in this paper. We measured the number of write topic of Twitter and blog about artists using the Hotlink and $\mathbf{M}$ data. The result show us that the Monthly number of WOM seems to be influenced by the event of each days.

Using Eq. (13) with the daily number of event of the Matsumoto Koushiro IX as the influence of the advertisement effect $\langle f(t)>$, we obtain the following result in Figure 4. We found in Figure 4 that our calculation of the intention to entertainment for Coldplay shows very well

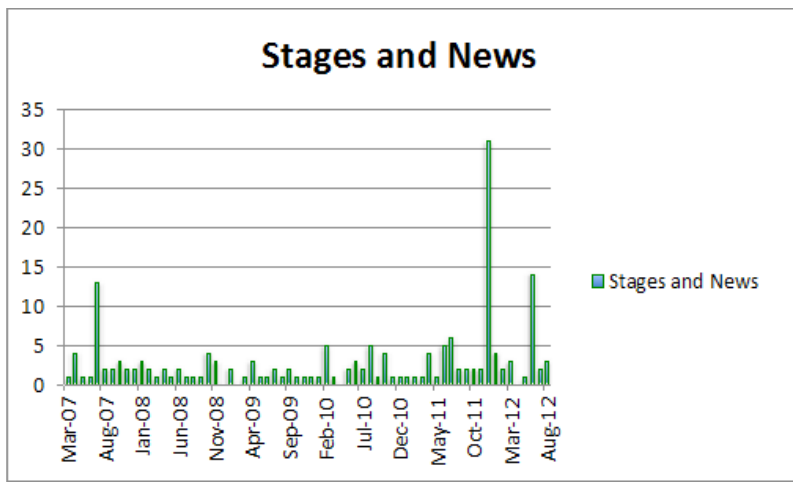

Figure 3: Matsumoto Koushiro IX.

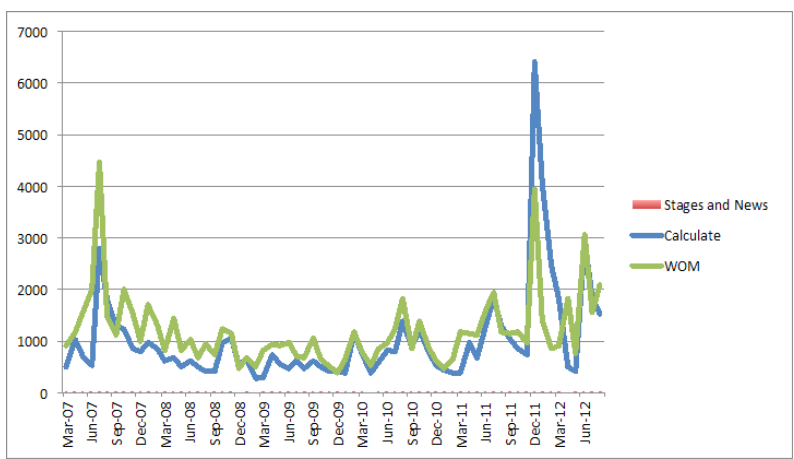

Figure 4: The calculation and the observed data for Matsumoto Koushiro IX, Kabuki Actor in Japan. The line means the observed number of Monthly posting of WOM/100 (Green) and Calculate (Blue). agreement with the real observed WOM, where the parameters in our calculation is adjusted using the Monte Carlo method to minimize the reliable factor $\mathrm{R}$ [2], the difference between the calculation curve and the observed WOM data.

From in Figure 5, Ichikawa Danjuro XII is a Kabuki actor who inherited the professional name from the Edo period. [15-17]

Due to the poor physical condition, the number of stage performances are few Ichikawa Danjulo of 2009-2013.

However, news of Ichikawa Danjulo was also reported more affected by the news of his son Ichikawa Ebizo and coverage of medical condition. [18-20]

However, the value of WOM and the calculated value was the result is very close as well with respect to Ichikawa Danjulo from Figure 5.

\section{DISCUSSION}

From Figures 2-4 and Table 1, 2, we found that our simulation can reproduce the monthly counts of Stage Actor reputation. In other words, the simulation can reproduce the same counts of intention for entertainment of the artists $[13,14]$.

And from Table 1, 2, a is low Matsumoto Koshiro, Danjuro from that it shows high value.

Danjuro shows that there is a tendency that topic have a tendency to disappear in the next month even if there is a stage and talk once. That poor health was the cause would be one of the causes.

We also found from the results of Cadv that reputation is quite high from the fact that Koshiro Matsumoto has appeared in many stage frequently.

We were possible with the present method may be analyzed to quantify the interior of the actor's reputation individual.

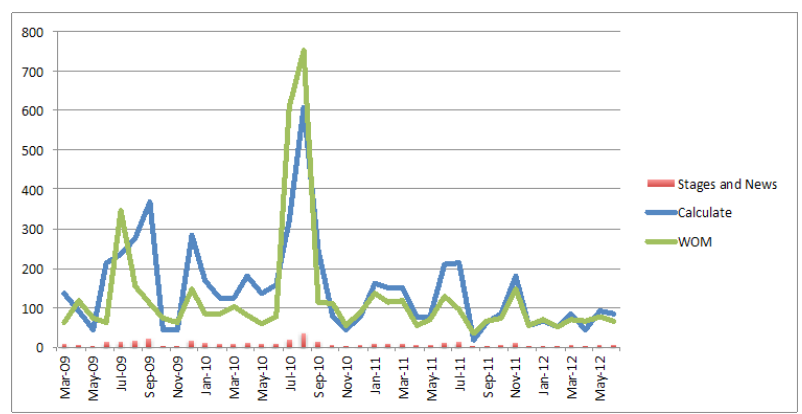

Figure 5: The calculation and the observed data for Ichikawa Danjuro XII, Kabuki Actor in Japan. The line means the observed number of Monthly posting of WOM/100 (Green) and Calculate (Blue) and Stage and News (Red). 
Table 1: Table of parameters for the Matsumoto Koushiro IX. Cadv is the strength of the advertisement; $a$ is the decline factor of the advertisement; Dnn is the direct communication factor; Pnn is the indirect communication factor. (1/month)

\begin{tabular}{lc}
\hline \hline Cadv & 195.39926623784203 \\
a & 0.6602 \\
NpDnn(before) & $1.2521767871338043 \mathrm{e}^{-0.05}$ \\
NpDnn & $5.1057384891031728 \mathrm{e}^{-0.05}$ \\
NpDny & 1.3755802908830963 \\
Np2Pnn(before) & $2.6047578364630221 \mathrm{e}^{-0.08}$ \\
Np2Pnn & $5.0991555442771686 \mathrm{e}^{-0.06}$ \\
Np2Pny & $4.9851179003749434 \mathrm{e}^{-0.06}$ \\
Np2Pyy & $4.8637686934045630 \mathrm{e}^{-0.06}$ \\
\hline \hline
\end{tabular}

Table 2: Table of parameters for the Ichikawa Danjuro XII. $\mathrm{Cadv}$ is the strength of the advertisement; $\mathrm{a}$ is the decline factor of the advertisement; Dnn is the direct communication factor; Pnn is the indirect communication factor. (1/month)

\begin{tabular}{ll}
\hline \hline Cadv & 16.931928869600309 \\
$\mathrm{a}$ & 16.535 \\
NpDnn & $5.0689392948419790 \mathrm{e}^{-0.05}$ \\
NpDny & 1.3695341660635636 \\
Np2Pnn(before) & $4.5538383691993215 \mathrm{e}^{-0.09}$ \\
Np2Pnn & $4.8180659312801924 \mathrm{e}^{-0.06}$ \\
Np2Pny & $4.9979624408771784 \mathrm{e}^{-0.06}$ \\
Np2Pyy & $4.8984567084331564 \mathrm{e}^{-0.06}$ \\
\hline \hline
\end{tabular}

As we found in the figures and tabeles our calculations using Eq. (13) agree very well with the observed monthly WOM data. Therefore, we can consider that the mathematical model for hit phenomena using Eq. (13) can be applied also for the Stage Actors. Since our theory is very general, it can be applied not only to the motion picture entertainment industry but also to many other fields including local events. Therefore, our theory can be used to investigate human-human interaction especially those meant for entertainment. The main assumption underlying our theory is that the price of the target is not expensive enough that the consumer would not be affected by the advertisement. Thus, when producing music concerts, the concerts producer can use our theory to estimate the rough number of tickets sold and reputation of the Stage Actor from concerts, TV appearances and news [1-3,13,14].

\section{CONCLUSIONS}

We apply the mathematical theory for revenue prediction of music concerts using the mathematical Model of hit phenomena and The calculation using our mathematical model for hit phenomena presents the intention to entertainment in the society. Since the intention to entertainment in the society is considered to be proportional to the number of positing of blogs or Twitter, we can compare our calculation with observed number of daily posting of blog and Twitter. In recent years, the social media like Facebook, Twitter and blogs has been very popular, so that the evaluation of arts, music and plays can be evaluated not only by the experts but also using the social media. Sometimes even great artists and works of art, it is not known to the public.

Strategy method to increase the opportunity to review as the masses know also becomes increasingly important in the future, such as going to the transmission of information while the prediction will become more necessary. For example, we must examine it for the advertising of the high quality artist and work to utilize this technique well.

We expect that it might be can be considered should it be elevated to cast theater and drama and CM, a movie in which timing from that prediction can be from a number of news stage and the reputation of the actor individual from the results of this method.

Residual problem is the difference in impact on the reputation of each actor that arise from differences in the number of news and stage that are in the input.

However, we'll be able to analyze the reputation of entertainment regardless of the genre by this method.

In addition, we are keen to trend-sensitive topic of family of actors. We're going to need more consideration to put consideration to human relations around the actor.

Lastly, Creation and the advertising of high quality contents will lead it to development and the promotion of culture of the world. And we expect the human being society which continues producing creation and discovery than a fight and war through this study.

\section{REFERENCES}

1. A Ishii, H. Arakaki, N. Matsuda, S. Umemura, T. Urushidani, N. Yamagata, and N. Yoshida; The 'hit' phenomenon: a mathematical model of human dynamics interactions as a stochastic process, New Journal of Physics, 14, 063018 (2012).

2. A Ishii, T Matsumoto and S Miki; Revenue Prediction of a Local Event Using the Mathematical Model of Hit Phenomena, Prog.Theor.Phys. Supplement, 194, 
pp.64-72 (2012).

3. A Ishii, K Furuta, T Oka, H Koguchi and K Uchiyama; Mathematical Model of Hit Phenomena as a theory for collective motion of human mind in societies, the Frontiers of Artificial Intelligence and Applications (FAIA) series (IOS Press) in press.

4. Allsop DT, Bassett BR, and Hoskins JA; Word-ofmouth research: principles and applications, J. Advertising Research, 47, p.398 (2007).

5. Kostka J, Oswald Y A, and Wattenhofer R; Lecture Notes in Computer Science, 2008, Word of Mouth: Rumor Dissemination in Social Networks, 5058, pp.185-196 (2008).

6. E. Bakshy, J. M. Hofman, W. A. Mason, and D. J. Watts; Everyone's an Influencer: Quantifying Influence on Twitter, In Fourth ACM International Conference on Web Seach and Data Mining (WSDM), Hong Kong, ACM, pp.65-74 (2011).

7. Jansen BJ, Zhang M, Sobel K, and Chowdury A; Twitter power: Tweets as electronic word of mouth, J. Am. Soc. Inform. Sci. Tech, 60, pp.2169-2188 (2009).

8. Brown, J. J., and Reingen, P. H; Social ties and wordof-mouth referral behavior, Journal of Consumer Research, 14 (3), pp.350-362,(1987).

9. Murray, K.B; A test of services marketing theory: consumer information acquisition activities, Journal of Marketing 55, pp.10-25 (1991).

10. Banerjee A; A Simple Model of Herd Behavior, The Quarterly Journal of Economics, 107(3), pp.797-817, 1992.

11. Taylor J; Word of Mouth Is Where It's At, Brandweek, Brandweek, 6/2/2003, 44(22), p.26 (2003).

12. Liu, Yong; Word-of-Mouth for Movies: Its Dynamics and Impact on Box Office Revenue, Journal of Marketing, 70(3), pp.74-89 (2006).

13. Akira Ishiil, Sho Ota, Hideo Koguchi and Koki Uchiyama; Quantitative analysis of social popularity for Japanese pop girl group AKB48 using mathematical model for hit phenomena, ICBAKE2013, unpublished.

14. Kawahata Y, Etsuo Genda and Akira Ishii; Revenue Prediction of Music Concerts Using the Mathematical Model of Hit Phenomena, ICBAKE2013, unpublished.

15. Scholz-Cionca, Stanca, and Samuel L. Leiter, eds.; Japanese theatre and the international stage, 12, Brill (2001).
16. Park Kumsoon; Kabuki legend Danjuro basks in the spotlight after long illness, Digital Communications and Privacy, The Asahi Shimbun Company, October 25, (2012) Retrieved.

17. Kabuki-bito; Available http://www.kabuki-bito.jp/eng/

18. Japan Arts Council; Available at, http://www2.ntj.jac.go.jp/dglib/

19. About TV Performer Ranking Japan; Available at, http://www.tv-ranking.com/

20. Kikuzou II vVisual; Available at, http://database.asahi.com/library2/

\section{Yasuko KAWAHATA}

Yasuko Kawahata is a Doctor's Course second year of Content and Creative Design , Faculty of Design Kyusyu University, Fukuoka, Japan. Mail:purplemukadesan@gmail.com

\section{Etsuo GENDA}

Etuso Genda is a Professor of Content and Creative Design Faculty of Design, Kyushu University, Fukuoka,Japan. He is conducting research on communication design on the premise of communication technology and computer research and representation in the media arts. Throughout the study of the representation of the virtual body, he is aiming to apply to various digital content and entertainment and medical education in recent years.

Mail:genda@design.kyushu-u.ac.jp

\section{Hidehiko KOGUCH}

Hidehiko Koguchi is Director of M-Data Inc. He also has his own company, Perspective Media, Inc. He participated in M-Data start-up just after he founded Perspective Media in 2007, since the both business are strongly related with his expertise of media development. He provides various types of marketing/social intelligence research and consulting works by combination results of two companies. He received a bachelor's degree of business \& commerce from KEIO University in 1984.

\section{Koki UCHIYAMA}

Koki Uchiyama is C.E.O. of Hottolink. He is visiting professor of University of Digital Hollywood, and teaching "community and agent." Mail:uchi@hottolink.co.jp

\section{Akira ISHII}

Akira Ishii is a Professor, Department of Applied Mathematics and Physics Tottori University, Tottori, Japan. And he is C.R.O FindPers Co.,Ltd. "Mathematical model of the hit phenomenon" is honored as Innovative Technologies, the Ministry of Economy, Trade and Industry in 2012. Mail: ishii.akira.t@gmail.com 